\title{
Filipina American women's breast cancer knowledge, attitudes, and screening behaviors
}

\author{
Celine M Ko ${ }^{1,2}$, Georgia Robins Sadler*2, Lisa Ryujin ${ }^{2}$ and Adam Dong ${ }^{2}$
}

\author{
Address: ${ }^{1}$ San Diego State University/University of California, San Diego Joint Doctoral Program in Clinical Psychology, San Diego, California, \\ USA and ${ }^{2}$ Rebecca and John Moores UCSD Cancer Center, University of California, San Diego, La Jolla, California, USA \\ Email: Celine M Ko - cmko@ucsd.edu; Georgia Robins Sadler* - gsadler@ucsd.edu; Lisa Ryujin - lryujin@ucsd.edu; \\ Adam Dong - gsadler@ucsd.edu \\ * Corresponding author
}

Published: 15 August 2003

BMC Public Health 2003, 3:27
Received: 04 February 2003

Accepted: 15 August 2003

This article is available from: http://www.biomedcentral.com/147/-2458/3/27

(C) $2003 \mathrm{Ko}$ et al; licensee BioMed Central Ltd. This is an Open Access article: verbatim copying and redistribution of this article are permitted in all media for any purpose, provided this notice is preserved along with the article's original URL.

\begin{abstract}
Background: Filipino Americans are the fastest growing Asian minority group in the United States. There is limited knowledge about their breast cancer knowledge, screening practices and attitudes.

Methods: As part of the evaluation of the Asian Grocery Store-Based Cancer Education Program, 248 Filipino American women completed baseline and follow-up surveys, while an additional 58 took part in focus groups.

Results: Compliance with annual clinical breast exam guidelines among women 40 to 49 years old was $43 \%$, and annual mammography use among women 50 and over was $56 \%$. The Asian Grocery Store-Based Cancer Education Program and complementary focus group study identified multiple barriers that hindered women from attending education programs, with time as the most frequently reported barrier.

Conclusion: The Asian Grocery Store-Based Cancer Education Program was reported to be a culturally acceptable and effective way of disseminating breast cancer information and one that addressed the women's most frequently reported barrier, lack of time.
\end{abstract}

\section{Background}

Asian women living in Asia are 40\% less likely to develop breast cancer than American women of Euro-white descent [1]. However, the longer women of Asian descent reside in the United States, the more closely their breast cancer incidence approximates that of White women [24]. Thus, it is important to encourage Asian American women to follow the American Cancer Society's (ACS) and National Cancer Institute's (NCI) breast cancer screening guidelines. A recent study assessed the breast cancer knowledge, attitudes, and screening practices of 1,202 Asian American women, as well as the overall socio- cultural acceptability and efficacy of offering a breast cancer education program at Asian grocery stores [5]. That study's data showed the community's potential to benefit from breast cancer education programs.

In the creation of optimal educational interventions, it is important to recognize that the Asian/Pacific Islander community is not entirely homogeneous. Few studies have been done with large enough samples to describe and understand the individual subgroups' patterns of cancer morbidity and mortality $[6,7]$ or their response to health promotion programs. Filipinos, the second largest 
Asian subgroup in the United States, show higher levels of acculturation compared to most other Asian sub-groups, but economic, language, and cultural barriers to health promotion programs and practices still remain [8]. To help advance the creation of breast cancer education programs specifically for Filipinas, this paper analyzes the data subset of Filipina women from the larger Asian Grocery Store-Based study [5,9-15]. The Asian Grocery StoreBased Study used the Health Belief Model [16] as its theoretical framework; knowledge was recognized as a necessary precursor to women's adherence to breast cancer screening guidelines. This paper also includes data collected from supplemental focus groups of Filipinas to provide a richer interpretation of the data and a better understanding of how to promote their health.

\section{Methods}

Asian grocery stores in San Diego County were anticipated to be culturally acceptable sites where Asian women of diverse cultures, ages, socioeconomic status, languages, and levels of acculturation could be educated about breast cancer and repeatedly cued to follow screening guidelines. A complete description of the larger Asian Grocery StoreBased Cancer Education Program is available (see Sadler, Nguyen, Doan, Au, \& Thomas, 1998). To ensure a sample of Filipinas, grocery stores that catered to the specific needs of the Filipino American community were recruited.

Bilingual Filipina undergraduate students from local universities were recruited and trained to work as community health educators (CHE) at the participating grocery store sites. The CHEs set up educational displays with ethnically aligned icons of the Filipino culture in front of the grocery stores. Educational literature in English and Tagalog, the leading Filipino language, and hands-on teaching models were provided. The CHEs also promoted access to the State's Breast Cancer Early Detection Program (BCEDP) that provided free mammograms to economically disadvantaged women. The local American Cancer Society's list of mammography centers and the cost of mammograms for women who did not qualify for the BCEDP screening were also distributed. Sunscreen samples were used as incentives to attract women to the educational displays and also as segue into a discussion of cancer screening practices.

Women were invited to participate in the evaluation of the program after they received the health information. Those who agreed to participate completed an IRBapproved consent document and a short baseline survey. The survey was self-administered in women's preferred language (English or Tagalog) with assistance from CHEs. Follow-up telephone surveys were initiated two weeks post intervention by the CHEs. Up to ten telephone attempts were made to contact the women for the followup survey. When telephone contact failed or was not an option, the follow-up surveys were mailed to those who had provided an address. A stamped, self-addressed envelope plus a personalized letter were also included.

To encourage participation and minimize subject burden, the self-report surveys were brief and included questions about barriers to health education, attitudes related to health, and breast cancer screening practices. The followup survey focused on the women's willingness and ability to schedule a breast cancer screening. Frequency counts, percentages and chi-square tests were used to analyze the data.

Simultaneously, focus groups of Filipinas, facilitated by a bilingual Filipina $\mathrm{CHE}$, were held in community settings to gain a more in-depth understanding of their views on breast cancer. Filipina women were recruited and asked to invite five or more acquaintances to a focus group. Participants completed a consent document and baseline survey before taking part in an hour-long breast cancer education program. At the conclusion of the program, they completed a follow-up survey and then participated in a focus group discussion guided by a series of openended questions related to common barriers to breast cancer control and myths, as well as ways to disseminate information about breast cancer early detection and treatment options. The Socratic teaching method was employed throughout to promote open discussion within the groups. Women's comments were noted and qualitatively analyzed after the focus group sessions. This method is consistent with recommendations on how to conduct qualitative research [17].

\section{Sample Descriptions \\ Grocery Store Sample}

Of the 1,202 Asian American women aged 20 years or older, 248 were Filipinas. The women in this subset were between the ages of 20 and 77 (mean $=44.6$ years, SD = 12 years). When women failed to report their age $(n=19)$, the CHEs estimated their age to facilitate evaluation of their adherence to screening guidelines by age group. These women were not included in the average age calculation, but were included in the assessment of their adherence to the ACS's recommended screening guidelines. Of these women, all were estimated to be well over 50 years old, and hence candidates for annual mammograms and clinical breast exams. The native language most commonly reported was Tagalog (91.1\% (226)), followed by English (6.9\% (17)), Ilocano (1.6\% (4)), and Spanish $(0.4 \%$ (1)). A review of ZIP codes and telephone exchanges showed the venues' ability to attract a geographically diverse sample. 
Table I: Women's Reported Adherence to Screening Guidelines* by Age Group at Baseline

\begin{tabular}{llll}
\hline Screening & Age: $20-39(n=73)$ & Age: $40-49(n=79)$ & Age: 50+ $(n=96)$ \\
\hline Breast Self-Exam & $33(45 \%)$ & $36(46 \%)$ & $41(43 \%)$ \\
Clinical Breast Exam & $28(38 \%)$ & $34(43 \%)$ & $45(47 \%)$ \\
Mammogram & N/A & $36(46 \%)$ & $46(48 \%)$ \\
\hline
\end{tabular}

*American Cancer Society guidelines in effect at the time of the study were: I.) Beginning at age 20, breast self-exams monthly and clinical breast exam every three years. 2.) Beginning at age 40 , clinical breast exams annually plus mammography every one or two years. 3.) Beginning at age 50 , annual clinical breast exams and mammograms along with monthly breast self-exams.

Table 2: Perceived Barriers to Adherence

\begin{tabular}{llll}
\hline Barrier & $\begin{array}{l}\text { Asian Grocery Store Group } \\
\text { Baseline }(\mathrm{n}=248)\end{array}$ & $\begin{array}{l}\text { Asian Grocery Store Group } \\
\text { Follow-up }(\mathrm{n}=17 \mathrm{I})\end{array}$ & $\begin{array}{l}\text { Focus Group at } \\
\text { Baseline }(\mathrm{n}=56)\end{array}$ \\
\hline Lack of time & $64 \%$ & $2 \%$ & $32 \%$ \\
Money & $13 \%$ & $12 \%$ & - \\
Did not want to think about it & $10 \%$ & - & $7.2 \%$ \\
Language & $7 \%$ & $1 \%$ & - \\
Not important & $4 \%$ & - & $3.6 \%$ \\
Embarrassing to discuss & $2 \%$ & - & - \\
Transportation & - & $5 \%$ & - \\
Fear & - & $6 \%$ & - \\
\hline
\end{tabular}

\section{Focus Group Sample}

Fifty-six women ages 20 to 76 years (mean $=37.8$ years, $\mathrm{SD}=13.74$ years) attended the focus group sessions. Nine women did not give their age and were not included in these age calculations. All of these women were estimated to be over 50 years old, and were included in screening adherence calculations.

\section{Results}

\section{Grocery Store Sample: Baseline Survey}

Women's adherence to breast cancer screening guidelines was highest among women age 50 and older (See Table 1 ). Eighty-seven percent (217) said that they would be interested in receiving free information to keep their families healthy, and $84 \%$ (207) said they would be willing to receive health information of a personal nature such as breast cancer. Ninety-two percent (229) of the women said they would be comfortable sharing the information with family and friends, and 70\% (174) believed that their family and friends would be interested in receiving any educational information they could pass along about breast cancer. When asked if they had enough knowledge about breast cancer, 35\% (86) said they did. When the women were asked if they were willing to be contacted for further questions regarding the current study, 76\% (189) said that they would be available for contact.
When asked about their preferred methods of receiving future health information, $68 \%(168)$ of the women were willing to receive mailed information, $31 \%$ (76) were willing to be called back, and $20.5 \%$ (51) were willing to attend an educational program. Continuing education sessions at the grocery store were not given as an option. When the women were asked if they were willing to participate in other similar research studies, 32\% (80) said they would.

\section{Grocery Store Sample: Follow-up survey}

Participants were called two weeks after completion of the baseline survey for follow-up. Sixty-nine percent (171) of the participants completed a follow-up survey, while $23.8 \%$ (59) were lost to follow-up, 5.6\% (14) refused to participate in the follow-up survey when contacted, and $1.6 \%$ (4) failed to be reached after 10 telephone attempts and did not return their mailed follow-up survey. Of the 171 women, $44 \%$ (75) reported setting up a screening exam. Ninety-two percent of these women reported that setting up a screening appointment was easy to do. These women set up their exams through clinics (32), hospitals (13), the BCEDP (2), and doctor's offices (2). Perceived barriers are reported in Table 2. Not surprisingly, only those who failed to set up an appointment reported barriers. The follow-up survey included an open-ended question asking the women what could be done to make the screening process easier; women reported interest in 
extended hours for the screening facilities, faster service, free screening, and transportation.

\section{Focus Groups: Baseline Survey and Follow-up Survey}

The primary purpose of the focus groups was to gather qualitative data related to breast cancer screening, as opposed to women's adherence to recommended screening guidelines. The data gathered, however, was consistent with the lower than optimal adherence rates reported by women in the grocery store samples and focus groups. Fifty percent (28/56) of the women reported having done a BSE in the past month. Of the 19 women 40 years and older, 37\% (7) reported having had a CBE in the past year, and $65 \%$ (13) reported having ever had a mammogram. Of the 10 women 50 years and older, $40 \%$ (4) reported having had a CBE in the past year, and 90\% (9) reported having ever had a mammogram.

The women's most commonly reported source of cancer information was a healthcare professional (61\% (34/ $56)$ ). This was followed by print media $(43 \%(24))$, television $(20 \%(11))$, family and friends $(12.5 \%(7))$, health education programs/community centers/school ( $9 \%(5))$, and the Internet (2\% (1)). Regardless of women's linguistic proficiency, reliance on their health care professional was reported to be most likely to determine whether women would take part in screening.

While only one woman reported lack of information as a barrier at baseline, the majority of the women demonstrated a significant lack of information on screening guidelines and general information about breast cancer. For example, while half (28) of the women reported having received previous breast cancer training, only half (14) of those women recognized that the best time to perform a BSE was not during one's menstrual period and only eight of those women recognized that the likelihood of cancer increases with age. Only 35\% (20/56) of all the women recognized that the important thing to look and feel for when doing a breast self-exam is changes from month to month.

Follow-up surveys with focus group participants were completed immediately after the training program intervention and prior to open focus group discussion. A significant increase in the desired knowledge was demonstrated. For example, $12.5 \%$ of the women at baseline were able to identify the correct age one should begin to do a BSE, in contrast to $84 \%$ after the educational intervention. Likewise, $64.3 \%$ identified the correct age to begin doing a CBE after the training compared to $10.7 \%$ of the women before the focus group training. Qualitatively, the greatest finding at follow-up was the women's realization of how much information they were missing. Misinformation was also commonplace, such as the belief that trauma to the breast could cause breast cancer. Equally critical was the pervasive belief that unless a woman's doctor recommended screening, it was unnecessary. These misconceptions were notably missing at follow-up.

\section{Discussion}

The below optimal breast cancer screening rates found in the study are comparable to those found in other studies, falling far below the targets set for the Year 2010 Healthy People Initiative [18]. Similar mammography screening rates ranging from $41 \%$ to $66 \%$ have been reported in other studies $[2,8,19]$. Overall, only $44 \%$ of the women reported doing a breast self-exam. While this is not the best method of early detection, it is the best option for interval screening among women of all ages. The demonstrated lack of breast cancer knowledge reported by the study participants may have contributed to the low screening adherence among the women. Previous studies have demonstrated that knowledge of breast cancer and screening guidelines is related to screening rates $[20,21]$ With only $34.7 \%$ of the women reporting that they had enough breast cancer knowledge, there is further evidence of the need for more focused cancer education programs.

It has been shown that barriers to screening adherence differs among different ethnic groups [22]. Among FilipinaAmericans in our sample, lack of time was the most frequently reported barrier to participation in educational programs in the grocery store sample and in the focus groups. This commonly reported barrier needs to be better understood. It could be considered a socially acceptable excuse for women who do not want to follow recommended screening guidelines. For other women who do not feel that breast cancer imposes a serious, immediate personal threat, this perceived barrier could be a reflection of the prioritization of breast cancer screening. On the other hand, this reported lack of time could be a reflection of Filipina's "bahala na" value, a belief that one need not worry about unpleasant circumstances because such events are beyond the individual's control [23].

Once this reported barrier is better understood, it may be possible to create a more culturally aligned intervention that will facilitate the screening action needed to detect breast cancer at the earliest possible stage. With a better understanding of this barrier, the Asian Grocery StoreBased Cancer Education program and other interventions could reach women with more culturally honed messages about the importance of screening. Further evaluation of this model is warranted to determine whether this educational program is truly as effective in helping women to adopt screening behaviors as this demonstration project suggests. 
The Asian Grocery Store Based Cancer Education program offered repeated health messages in a safe and culturally sensitive environment that addressed the cultural values of different Asian subgroups. For example, "pakikisama" in Filipina women reflects a value concerning interpersonal communication, and is purposive so that conflict can be avoided and harmony maintained [23]. Women who hear about breast cancer information may "give in" or agree to what they learn even if they hold contradictory beliefs, to avoid conflict and maintain harmony with the CHEs. It is important to persist in sending important messages about the importance of breast cancer education so that Filipina women who may seem compliant to learning about it at first, can be convinced of its value.

Women reported a high reliance and trust in the health information provided by their health care provider as well as in the health information provided by the media. This is consistent with earlier studies reporting that a physicians' recommendation is the strongest predictor of screening $[24,25]$. Encouraging health care providers to deliver and reinforce breast cancer early detection screening measures is critical. Sixty one percent of women in the focus groups identified healthcare professionals as their primary source of health and cancer information. With $43 \%$ of the women in the focus groups reporting print media as a key source of health information, collaborations with electronic and print media offer another important way to bring health information to Filipinas [26-29].

Equally important, women in both samples said that they would be willing to share any health information they received with others. In the larger sample, 92\% of the women said they were willing to discuss these facts with their friends and family. Previous studies also suggest that Filipina women readily seek counsel from friends and family who have already experienced related health events [30]. This communication network used by Filipinas could be a powerful tool to enable health educators to amplify their health messages to other, especially older, members of the family and friends.

\section{Limitations}

The data were drawn from a convenience sample within only one, albeit large, geographic region. The very act in taking part in the study's educational program, the consenting process and data collection could have created a sample of women that is not representative of all Filipinas. The data collection instruments have not previously been validated. Since the women were usually on their way in to shop or on their way out of the grocery stores, the survey was meant to be quick assessment of the women's knowledge, attitudes, and practices. Finally, being a demonstration study rather than a randomized clinical trial, there is no assurance that the reported increase in screening rates post-intervention were the result of the intervention rather than chance alone. Alternately, social desirability was not assessed; women could have given answers that they thought would please the CHEs. Given these limitations, the reported findings must be applied with caution. However, for at least a proportion of Filipina women, the data offers insight into their prevailing breast cancer knowledge, attitudes, and behaviors, and demonstrates the importance of gaining a better understanding of the individual ethnic subgroups that are included and stereotyped within the category of Asian American.

\section{Conclusion and Future Directions}

This convenience sample of Filipinas in San Diego County has less than optimal screening rates. However, this group's willingness to learn and share their breast cancer information with others can be a way to extend the provision of culturally sensitive training programs and health care providers' screening recommendations. The Asian Grocery Store-Based Cancer Education Program is easy for Filipinas to access and appears to be an acceptable and culturally aligned method of encouraging women to adhere to recommended breast cancer screening guidelines. Future studies could include assessment of Filipina women's cultural and demographic variables to better assess how the group's cultural and socioeconomic backgrounds affect their health behaviors. Some cultural and demographic variables that will be important to study include acculturation, length of stay in the United States, level of education, socioeconomic status, religiosity, and strength of ethnic identity.

Follow-up surveys were completed two weeks after baseline. Future studies could include long-term effects of the intervention, with screening rates assessed a year or six months after contact with the CHEs. This may be a more valid way of surveying whether women were able to set up appointments with their physicians to be compliant with screening guidelines since it usually takes longer than two weeks to schedule these exams.

\section{Competing Interests}

None declared

\section{Authors' contributions}

GS conceived of the study and participated in its design and coordination, as well as preparation of this manuscript. CK performed the statistical analysis and drafted the manuscript. AD and LR participated in the preparation of this manuscript. In addition, LR was a community health educator and was involved in education at the grocery stores. All authors read and approved the final manuscript. 


\section{Acknowledgements}

This project was funded by a San Diego and Imperial County Breast Cancer Early Detection Regional Partnership grant, a Susan G. Komen Breast Cancer Foundation Special Populations grant, and a National Cancer Institute grant R25-CA65745. A Doris Howell Foundation Scholarship enabled Jayme del Rosario, a UCSD undergraduate, to conduct the focus group's study component. The manuscript's contents are the sole responsibility of the authors and do not necessarily represent the official beliefs of the funding agencies.

The authors also wish to thank the American Cancer Society, the National Cancer Institute, and the San Diego Union of Pacific Asian Communities for their guidance and generous contribution of printed educational materials and videotapes. The following companies are also recognized for their generous contribution of the sunscreen product samples distributed during the cancer education program: Almay; Arizona Sun; Banana Boat; Blistex; Bristol Myers Squibb; Bullfrog; Clinique; Coppertone; Doak; Mary Kay; Merle Norman; Physician's Formula; and Schering Plough.

Finally, the authors wish to thank the hundreds of UCSD undergraduate students who participated in the implementation of this project, and the following owners and managers of the Asian grocery stores who shared the common vision of enhancing their community's health: Diwali Festival; First Market; Hing Long Market; India Sweets and Spices; Manila Seafood Market; Neema's Sari Palace; Nijaya Market; Philippine-American Expo; San Diego Supermarket; Seafood City, National City; Seafood City, Chula Vista; Vien Dong, San Diego; Vien Dong III, San Diego; Vien Dong IV, San Diego; 99 Ranch Market, San Diego; 66 Ranch Market, San Diego; 79 Supermarket, EI Cajon; 79 Supermarket, Mira Mesa; 79 Super Market, San Diego; and Yaohan Mitsuwa.

\section{References}

I. Stanford JL, Herrinton LJ, Schwartz SM and Weiss NS: Breast cancer incidence in Asian migrants to the United States and their descendants. Epidemiology 1995, 6:181-183.

2. Maxwell AE, Bastani R and Warda US: Demographic predictors of cancer screening among Filipino and Korean immigrants in the United States. Am J Prev Med 2000, 1 8:62-68.

3. Nebres MV, Mark HF: Breast cancer among Asian women. Med Health R I I996, 79:388-39I.

4. Ursin G, Wu AH, Hoover RN, West DW, Nomura AM, Kolonel LN, Pike $M C$ and Ziegler RG: Breast cancer and oral contraceptive use in Asian-American women. Am J Epidemiol 1999, I 50:56I-567.

5. Sadler GR, Thomas AG, Yen JY, Dhanjal SK, Ko CM, Tran CH and Wang K: Cancer education program based in Asian grocery stores. Journal of Cancer Education 2000, I 5: I73-177.

6. US Census Bureau: Statistical Abstract of the U.S. Washington DC, U.S. Census Bureau; 1999:23-26,32,52.

7. Bernstein L, Miu A, Monroe K, Henderson BZ and Rose RK: Cancer incidence among Filipinos in Los Angeles County. International Journal of Cancer 1995, 63:345-348.

8. Maxwell AE, Bastani R and Warda US: Misconceptions and mammography use among Filipino- and Korean-American women. Ethn Dis 1998, 8:377-384.

9. Sadler GR, Nguyen F, Doan Q, Au H and Thomas AG: Strategies for reaching Asian Americans with health information. Am J Prev Med 1998, I 4:224-228.

10. Sadler GR, Wang K, Wang M and Ko CM: Chinese women: behaviors and attitudes toward breast cancer education and screening. Womens Health Issues 2000, 10:20-26.

II. Sadler GR, Dhanjal S, Bhatia N, Shah RB, Ko CM, Anghel M and Harshburger RJ: Asian Indian Women: Knowledge, attitudes and behaviors towards breast cancer early detection. Public Health Nursing 2001, I 8:357-362.

12. Sadler GR, Dong H, Ko CM, Ngyuyen H and Luu TT: Vietnamese American women and breast cancer early detection. Health Promotion 2001, I 5:21|-214.
13. Sadler GR, Ryujin L, Ko CM and Nguyen E: Korean Women: Breast cancer knowledge, attitudes, and behaviors. $B M C$ Public Health 200I, I:7.

14. Sadler GR, Takahshi M and Ko CM: Japanese women: behaviors and attitudes toward breast cancer education and screening. Health Care for Women International 2003, 24:18-26.

15. Sadler G, Ryujin L, Oh G, Nguyen T, Paik G and Kustin B: Heterogeniety within the Asian American community. (Submitted); 2003.

16. Becker $\mathrm{MH}$ : The health belief model and personal health behavior. Thorofare, N. J., C. B. Slack,; 1974.

17. Morgan DL: Focus groups as qualitative research. Newbury Park, CA, Sage Publications; 1988.

18. Healthy people 2010 2000, 2000: [http://www.healthypeople.gov/ about/goals.htm]. National Institute of Health

19. Maxwell AE, Bastani $R$ and Warda US: Breast cancer screening and related attitudes among Filipino-American women. Cancer Epidemiol Biomarkers Prev 1997, 6:719-726.

20. Valdez A, Banerjee K, Ackerson L, Fernandez M, Otero-Sabogal R and Somkin C: Correlates of breast cancer screening among lowincome, low-education Latinas. Preventive Medicine: An International Journal Devoted to Practice \& Theory 200I, 33:495-502.

21. Champion $V$ and Miller $A$ : Recent mammography in women aged 35 and older: Predisposing variables. Health Care for Women International 1996, I 7:233-245.

22. Miller A and Champion V: Attitudes about breast cancer and mammography: Racial, income, and educational differences. Women and Health 1997, 26:41-63.

23. Wilson $\mathrm{S}$ and Billones $\mathrm{H}$ : The Filipino elder: Implications for nursing practice. Journal of Gerontological Nursing 1994:3 I-36.

24. Friedman LC, Moore A, Webb JA and Puryear LJ): Breast cancer screening among ethnically diverse low-income women in a general hospital psychiatry clinic. Gen Hosp Psychiatry 1999, 2I:374-38I.

25. Thomas SM and Fick AC: Women's health. Part II: Individual, environmental and economic factors affecting adherence to recommended screening practices for breast cancer. J La State Med Soc 1995, I47:149-155.

26. The Susan G. Komen Breast Cancer Foundation: Asian or Pacific Islanders: Developing effective cancer education print materials. The Susan G. Komen Breast Cancer Foundation; 1997.

27. National Institutes of Health: Clear and Simple. Edited by: Nationa Cancer Institute. U.S. Department of Health and Human Services, National Institutes of Health; 1991.

28. Glanz K and Rimer B: Theory at a Glance. A Guide for Health Promotion Practice National Institutes of Health; I997:pp. 33-4I.

29. Brawley EA: Human services and the media. Newbury Park, CA, Sage Publications; 1995.

30. Berg JA and Lipson JG: Information sources, menopause beliefs, and health complaints of midlife Filipinas. Health Care Women Int 1999, 20:81-92.

\section{Pre-publication history}

The pre-publication history for this paper can be accessed here:

http://www.biomedcentral.com/1471-2458/3/27/prepub 